\title{
Proton Transfer Reaction Studies of Multiply Charged Proteins in a High Mass-to-Charge Ratio Quadrupole Mass Spectrometer
}

\author{
Rachel R. Ogorzalek Loo, ${ }^{*}$ Brian E. Winger, ${ }^{\dagger}$ and Richard D. Smith \\ Chemical Methods and Separations Group, Chemical Sciences Department, Pacific Northwest Laboratory \\ Richland, Washington, USA
}

Proton transfer reactions of multiply charged ions at high mass-to-charge ratios were explored with a low frequency quadrupole mass spectrometer. This instrument enabled a qualitative comparison of proton transfer reaction rates at low charge states for ions generated by electrospray ionization (ESI) from different solution conformations and for disulfide-linked versus disulfide-reduced protein ions. Proton transfer reactions that efficiently reduced the number of charges for ESI-generated ions to approximately the number of arginines in the polypeptide sequence were observed. No significant differences in gas-phase reaction rates were noted between different solution conformers. Differences in reaction rates between "native" and disulfide-reduced proteins were much smaller than those observed below $\mathrm{m} / \mathrm{z} 2000$ with lower proton affinity reagents or by using lower reagent concentrations. These smaller differences in reaction rates are thought to reflect the reduced electrostatic contributions from widely spaced charge sites and thus, the reduced sensitivity to an ion's three-dimensional structure or "compactness." (j) Am Soc Mass Spectrom 1994, 5, 1064-1071)

$\mathrm{R}$ ecently we presented data from the exploration of ion-molecule reactions as probes of higher order structure in multiply charged gas-phase proteins [1-3]. These electrospray ionization (ESI) studies showed that both proton transfer and hydrogen/deuterium (H/D) exchange reaction rates were sensitive to the presence or absence of disulfide bonds in proteins, which include lysozyme, albumin, aprotinin, $\alpha$-lactalbumin, and proinsulin. We have suggested that the increased reactivity differences arose from increased electrostatic repulsion for the more compact disulfide-linked proteins compared to the less constrained structure after reduction of disulfide bonds. However, proton transfer studies did not show convincing differences in reactivity for ions that arise from different protein conformations and are unconstrained by disulfide bonds [3], although differences in $H / D$ exchange rates and total exchange for protein conformers were demonstrated by Suckau et al. [4] and suggest that at least some elements of higher order protein structure can be preserved in the transition from solution phase to gas phase by the electrospray process. Differences in collision cross sections for cytochrome c

Address reprint requests to Dr. Richard D. Smith, Chemical Methods and Separations Group, Chemical Sciences Department, Battelle Pacific Northwest Laboratories, Battelle Boulevard, P8-19, P.O. Box 999, Richland, WA 99352.

* Current address: Protein and Carbohydrate Structure Facility, 2552 MSRB II, University of Michigan, Ann Arbor, MI 48109-0674.

Current address: Extrel FTMS, 6416 Schroeder Road, Madison, WI $53711-2424$. conformers with argon target gas $[5,6]$ provided further support for at least some retention of higher order structure in the gas phase.

The present study extends our exploration of proton transfer reactions to higher mass-to-charge ratio (lower charge) by using a low frequency quadrupole mass spectrometer (LFQMS). In this extension two questions are examined:

1. Do the low charge state products $(\mathrm{m} / \mathrm{z}>2000)$ from proton transfer reactions with ions generated from different solution conformations provide evidence for preservation of higher order structure to the gas phase?

2. To what extent does the proton transfer reaction proceed?

Our previous studies examined reaction rate differences for equally charged ions (of $\mathrm{m} / \mathrm{z}<2000$ ) with ammonia, dimethylamine, diethylamine, and trimethylamine as the proton transfer reagents $[1,3]$. In several cases, small differences in product charge state distributions were observed for ions that arise from different protein conformers, but we cannot exclude the possibility that these differences arose solely from differences in initial charge state distributions. By driving the proton transfer reactions farther, that is, to lower charge state products, it may be possible to lessen the dependence of the experiment on initial conditions and thus better address the first question. 
Reaction rates become successively slower at lower and lower charge states $[4,7]$. By focusing on differences in these slow rates, differences in the initial charge state distributions should be less important because the high charge states should react away quickly.

Question 2 is of interest for several reasons. The determination of how far the proton transfer reactions proceed provides information relevant to the electrostatic contributions to proton transfer for large ions. For example, the observation of significant reaction of ammonia with multiply charged proteins is initially surprising if it is examined only in the framework of proton affinities of isolated amino acids $[3,8,9]$, yet it is less surprising when the role of charge repulsion is considered. Another consideration is that if individual charge sites on a protein or polypeptide are distant enough, they should react at rates that approach that of a chemically similar charge site in a singly charged peptide (discounting higher order structural effects). One wonders if, in favorable cases and with large enough charge spacing, the likely charge sites can be assigned based un protein sequence and proton affinities. It can be imagined that by modeling the electrostatic or Coulomb contributions for a molecule with only a few charges and by comparing the model to experiment, one would indirectly obtain information about the distance between charge sites and the shape of the molecule. Of course, this dream presupposes that there are preferred locations for the protonated sites. However, for our experiment the location of $n$ charges in the product ion may be kinetically controlled (i.e., not reflect the energetically lowest placement of charges), and it is conceivable that the gasphase ions display considerable heterogeneity in the location of charge sites, for example, two kinds of $3+$ ions. Thus, by examining how far the proton transfer reactions proceed, potentially we can learn more about electrostatic contributions and provide a basis for rationalizing the slow reactions observed for low-charged molecules with preferred locations for protonation. Clearly, proton transfer reactions that yield ions beyond $\mathrm{m} / \mathrm{z} 2000$ have the potential to provide very interesting information and may open the door to new applications of ion-molecule chemistry.

\section{Experimental}

Application of the inlet-reactor approach to proton transfer reactions of multiply charged ions has been described elsewhere $[1-3,10-13]$, so only a brief description of the apparatus is provided in this report. Related approaches have been pursued by Feng and Konishi $[8,9]$ and Ikonomou and Kebarle [14]. These experinents differ from previous quadrupole ion trap $[7,15-17]$ and Fourier transform mass spectrometer [4] (FTMS) studies in that reactions occur in the atmospheric pressure-vacuum interface, which employs higher reagent gas flows. Reactions in the high pres- sure environment can reflect both bi- and termolecular collisions. These higher gas flows ensure that the reactions proceed sufficiently far during the millisecond ion transit through the inlet-reactor such that they reflect contributions from slower proton transfer reactions than those studied in the quadrupole ion trap [7, 15].

The electrospray ionization atmosphere-vacuum interface employed a $Y$-shaped inlet-flow reactor constructed from three lengths of 0.16-cm-o.d., 0.05-cm-i.d. stainless steel tubing. Inlet-reactors were fabricated either by silver soldering the tubing to a stainless steel post drilled with a 0.1-cm-dia. Y-shaped channel [1, 3, $10,11]$ or by attaching the tubing to a $1 / 16$-in. Swagelock stainless steel tee fitting $[2,12]$. One arm of the $Y$-tube transported ions, while the other arm delivered the neutral proton transfer reagent. Mixing of the two gas streams occurred in the Y-shaped channel (or Swagelock tee) and the third arm delivered the mixture to the mass spectrometer. An interaction time of approximately $20 \mathrm{~ms}$ is estimated for the protein ions with the reagent.

The capillary was electrically heated with currents of 11.0-14.5 A to desolvate the droplets [18, 19]. Capillary temperatures were determined by a chromelalumel thermocouple attached to the outer wall of the atmospheric pressure side of the inlet. (Actual gas temperatures are expected to be lower than the indicated inlet wall temperatures because of incomplete heat transfer.) Countercurrent gas flow $\left(\mathrm{N}_{2}\right)$ also assisted in desolvation for some of the studies reported here. Additional desolvation was achieved by collisional dissociation in the capillary outlet-skimmer (OS) region with potential differences of 25-400 V.

Because collisional dissociation in the OS region can supply very high internal energies, which possibly lead to deprotonation, there was some concern that charge distributions produced by reaction in the capillary might be altered by collisions downstream. Product charge distributions therefore were compared at different OS voltages. Distributions differed by one charge state, at most, between the highest and lowest OS voltages used. This observation may reflect small contributions due to charge stripping or energy-dependent transmission in the mass spectrometer. Earlier studies [3] performed on a different instrument did not show a shift in product charge state distribution with collision energy.

Bccause the proton transfer occurs in the capillary reactor, desolvation may not be complete before reaction. Operation at low OS voltages in the absence of reagent yielded spectra that did not indicate excessive solvation. Because of the low resolution of the instrument, we cannot preclude the possibility that some small fraction of the ions were solvated by a few molecules.

The primary difference in these experiments from those reported earlier $[1,3]$ is that a low frequency quadrupole mass spectrometer that spanned a $\mathrm{m} / \mathrm{z}>$ 
40,000 range was employed $[13,20]$. The instrument was based on an rf power supply oscillating at 292 $\mathrm{kHz}$ rather than the 1.2 to $1.5 \mathrm{MHz}$ typically employed. Ion detection usually employed a continuous dynode electron multiplier, although some work was performed with $20-\mathrm{kV}$ post-acceleration.

Trimethylamine (proton affinity $232.7 \mathrm{kcal} / \mathrm{mol}$ ) [21] was delivered through a pressure regulator (atmosphere delivery) and a needle valve. Triethylamine, a liquid at room temperature (proton affinity 239.6 $\mathrm{kcal} / \mathrm{mol}$ ) [22a], was introduced as a mixture with room air by employing a bubbler assembly upstream of the shut-off and needle valves. Mass flows for particular needle valve settings were determined by measuring the evacuation rate of calibrated gas sampling bags [3]. When 1,6-hexanediamine, a solid at room temperature (earlier measurements reflect a proton affinity $12.6 \mathrm{kcal} / \mathrm{mol}$ higher than TMA [22b]), was employed, the gas delivery tubing and bubbler assembly were heated to melt the reagent. The gas lines were maintained at a higher temperature than the bubbler assembly to prevent solidification in the gas lines.

One of the first experiments performed with our inlet-reactor provided confirmation that protein charge state distributions did not change upon addition of air flowing through the assembly at various needle valve settings. The results demonstrated that any shifts in protein charge state distributions observed with amine reagents arose from reaction with the amine and were not artifacts generated by the change in flow rate through the inlet-reactor.

All biochemical samples were obtained from Sigma Chemical Company (St. Louis, MO), with the exception of bovine proinsulin (Novo BioLabs, Danbury, CT). Triethylamine, trimethylamine, and 1,6-hexanediamine were acquired from Aldrich Chemical (Milwaukee, WI). Reduction of disulfide bonds in bovine $\alpha$-lactalbumin and bovine proinsulin was accomplished overnight at $37^{\circ} \mathrm{C}$ and for $1 \mathrm{~min}$ at $80^{\circ} \mathrm{C}$ in distilled water with 1,4-dithiothreitol (DTT). The protein-DTT solutions were acidified and studied by ESI mass spectrometry immediately following reduction.

\section{Results and Discussion}

A detailed discussion of the considerations and assumptions employed in inlet-reactor proton transfer experiments is provided in ref 1 . These assumptions are needed for the data interpretation to compare reactivities of ions generated from different solution structures because our approach shows the combined effects of the reaction for all charge states, as opposed to ion trapping mass spectrometers where isolation of a single charge state enables its reaction rate to be measured directly. The assumptions employed are (1) that the reaction rates are much faster for the higher charge states than for the low charge states and (2) that the $[\mathrm{M}+n \mathrm{H}]^{n+}$ charge state reacts to form an $[\mathrm{M}+(n-$ 1)H] $]^{(n-1)+}$ charge state with reactivity equal to that of the $[\mathrm{M}+(n-1) \mathrm{H}]^{(n-1)+}$ species formed originally by ESI.

\section{Reactivity of Ions Electrosprayed from Different Solution Conformations}

Figure 1a shows the mass spectrum obtained from bovine cytochrome $c\left(M_{v}=12,231\right)$ electrosprayed in $5 \%$ acetic acid / 1:1 methanol:water with an OS bias of $95 \mathrm{~V}$ and a capillary temperature of $160{ }^{\circ} \mathrm{C}$. Charge states from $[\mathrm{M}+5 \mathrm{H}]^{5+}$ to $[\mathrm{M}+13 \mathrm{H}]^{13+}$ were prominent. (The apparent bimodal charge distribution is not experimentally significant.) The charge state of maximum intensity obtained with this instrument $([\mathrm{M}+$ $11 \mathrm{H}]^{11+}$ ) is approximately five charge states lower than that obtained on other quadrupole instruments. We attribute this difference primarily to discrimination against low mass-to-charge ratio ions by the LFQMS [13].

Upon addition of $5.7 \times 10^{6} \mathrm{~mol} / \mathrm{s}$ of triethylamine (TEA), the cytochrome $c$ charge distribution shifts to the $[\mathrm{M}+4 \mathrm{H}]^{4+}$ and $[\mathrm{M}+3 \mathrm{H}]^{3+}$ ions, as illustrated in Figure $1 \mathrm{~b}$. A cytochrume c dimer species $[2 \mathrm{M}+5 \mathrm{H}]^{5+}$ also appears in the TEA-reacted spectrum and $[\mathrm{M}+$ $2 \mathrm{H}+3$ TEA $]^{2+}$ and $[\mathrm{M}+\mathrm{H}+3$ TEA $]+$ (not shown) also are observed, although the resolution is insufficient to resolve multiple TEA adducts for these two ions. The optimum OS bias for detection of these product ions was determined to be $155 \mathrm{~V}$ and those conditions were used to obtain Figure 1b. Clearly, condensing the cytochrome $\mathrm{c}$ spectrum into two charge states greatly improves the signal-to-noise ratio. Even

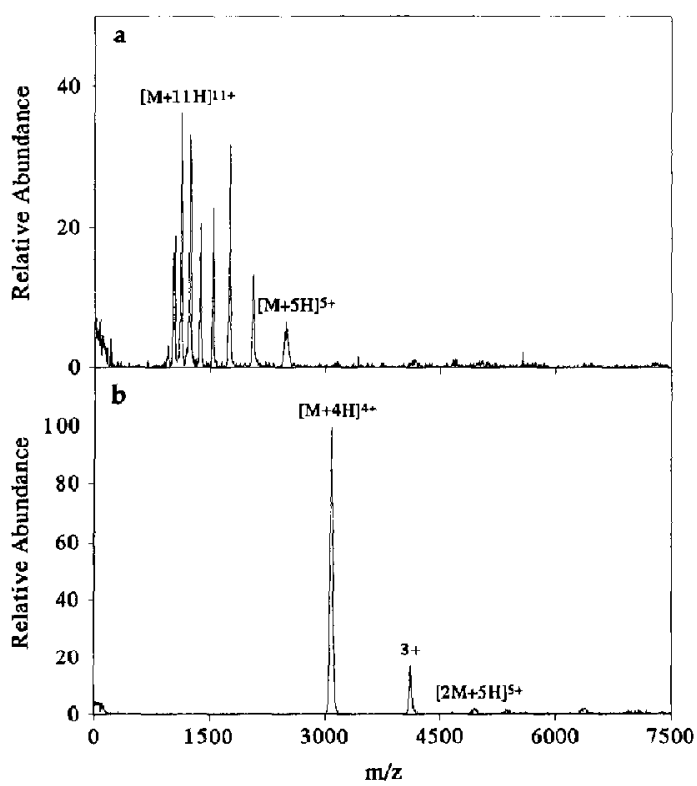

Figure 1. (a) ESI mass spectrum of bovine cytochrome $\mathrm{c}$ in $5 \%$ acetic acid/1:1 methanol: $\mathrm{H}_{2} \mathrm{O}, \mathrm{OS}=95 \mathrm{~V}$ and (b) under the same conditions, but with $5.7 \times 10^{-6}$-mol/s TEA and $O S=155$ 
when intensities of TEA-reacted and -unreacted ions are compared at the same OS voltages (nonoptimal for the low charge states), it is obvious that the [M+ $3 \mathrm{H}]^{3+}$ and $[\mathrm{M}+4 \mathrm{H}]^{4+}$ ions have increased in intensity by at least 30 times.

For the comparison of ion-molecule reactions with ions produced from a different solution conformer, bovine cytochrome $\mathrm{c}$ was electrosprayed from a $\mathrm{H}_{2} \mathrm{O}$ solution [23] with a $\mathrm{H}_{2} \mathrm{O}$ sheath (Figure 2a). Chait and co-workers [23] previously correlated the different ESI mass spectra at various solution $\mathrm{pH}$ with different protein conformers. Addition of $5.7 \times 10^{-6} \mathrm{~mol} / \mathrm{s}$ of TEA (Figure $2 b$ ) yielded results similar to those obtained from FSI of denatured cytochromer. Clearly, no differences attributable to gas-phase higher order structure were observed.

Reactions of cytochrome c electrosprayed from an aqueous $5 \%$ acetic acid solution with 1,6-hexanediamine protein transfer reagent also were explored. An amine flow of $3.0 \times 10^{-6} \mathrm{~mol} / \mathrm{s}$ shifted the charge distribution to the $4+$ to $2+$ charge state range, with the $[\mathrm{M}+4 \mathrm{H}]^{4+}$ as the charge state of maximum intensity. Increasing the reagent flow to $9.6 \times 10^{-6}$ - $\mathrm{mol} / \mathrm{s}$ yielded the same three charge states, but with [M + $3 \mathrm{H}]^{3+}$ now as the maximum intensity charge state. It is interesting that similar flow rates of hexanediamine and triethylamine yielded similar product charge state distributions, despite the differences in proton affinity. This failure to observe a difference between the two reagents may arise because (1) the inlet-reactor experiments may reflect reaction kinetics more than thermodynamics, (2) despite the differences in proton affinity

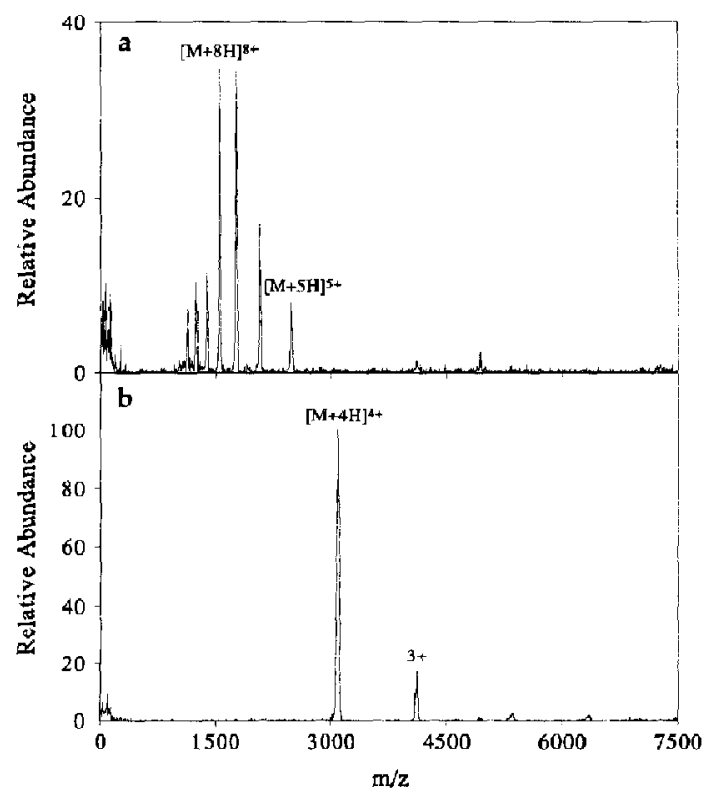

Figure 2. (a) ESI mass spectrum of bovine cytochrome $c$ in $\mathrm{H}_{2} \mathrm{O}, \mathrm{OS}=95 \mathrm{~V}$ and (b) under the same conditions, but with $5.7 \times 10^{-6} \mathrm{~mol} / \mathrm{s}$ TEA and $O S=155 \mathrm{~V}$. between TEA and hexanediamine, their gas-phase basicities are similar $(224.5$ and $223.0 \mathrm{kcal} / \mathrm{mol}$, respectively [22b]; the high proton affinity of hexanediamine arises because it dicoordinates a proton, which may be less likely at the temperatures we employed), and (3) the proton affinities of the last three to four charge sites may be larger than those of either reagent. Proton affinity measurements on isolated residues have shown that Arg $>$ Lys $>$ His and His $=228.5 \mathrm{kcal} / \mathrm{mol}$, Lys $=242.6 \mathrm{dcal} / \mathrm{mole}$, and Arg $>243.2 \mathrm{kcal} / \mathrm{mol}$ [22a]. These measurements have revised the order of amino acid protein affinities measured in previous work [24, 25]. The residues and charges neighboring a charge site in a protein also should affect its proton affinity. The bovine cytochrome c sequence has 2 arginines, 3 histidines, and 18 lysines. It could be argued that the three to four charges remaining on cytochrome $c$ after reaction with TEA or 1,6-hexanediamine reflect primarily Arg residues, due to the high proton affinity of that isolated amino acid. Internal cyclizations that al low two basic groups to interact with a proton are also possible.

Noncovalent interactions and conformational effects in horse heart myoglobin have been popular targets of study for a number of groups [26, 27]. ESI of myoglobin in 5\% acetic acid $1: 1$ methanol: $\mathrm{H}_{2} \mathrm{O}$ yields the apo-protein $\left(M_{r}=16,951\right)$ [28]. Charges from $16+$ to $4+$ are observed with the LFQMS with the maximum intensity for $[\mathrm{M}+11 \mathrm{H}]^{11+}$ (Figure 3a). Once again, we do not believe that the bimodal charge state distribution is significant; it probably reflects the combination of the "true" charge state distribution with the mass

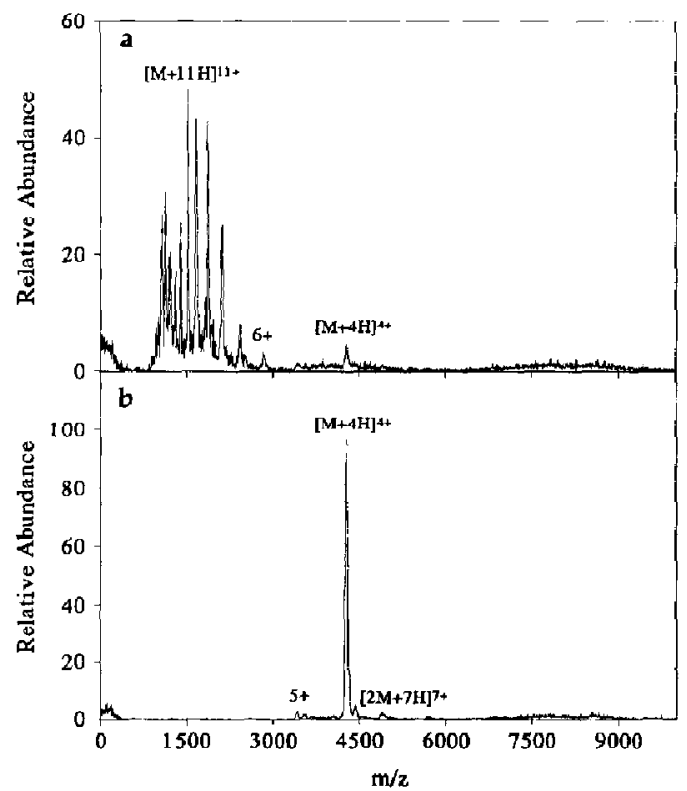

Figure 3. (a) ESI mass spectrum of horse heart myoglobin in $5 \%$ acetic acid/1:1 methanol: $\mathrm{H}_{2} \mathrm{O}$ and (b) as above, but with $1.8 \times$ $10^{-5}-\mathrm{mol} / \mathrm{s}$ TEA 
spectrometer's increased sensitivity at higher mass-tocharge ratio. A capillary temperature of $185^{\circ} \mathrm{C}$ and an OS bias of $75 \mathrm{~V}$ were employed. Addition of $1.8 \times 10^{-5}$ $\mathrm{mol} / \mathrm{s}$ of TEA shifts the charge distribution to primarily $[\mathrm{M}+4 \mathrm{H}]^{4+}$ (see Figure $3 \mathrm{~b}$ ).

ESI mass spectrometry of an aqueous myoglobin solution shows both apo- and holo-myoglobin ions (i.e., heme absent and attached, respectively), and the charge states ranged from $16+$ to $4+$ (See Figure 4a). For more gentle atmosphere-vacuum interface conditions, the holo-protein dominates the myoglobin $/ \mathrm{H}_{2} \mathrm{O}$ spectrum. For the harsher interface conditions employed in Figure 3, both forms of the protein were produced (compare Figures $3 a$ and $4 a$ ). Detachment of heme in the atmosphere-vacuum interface may occur by thermally induced dissociation [18] or by collisional dissociation. Reaction with $1.8 \times 10^{-5} \mathrm{~mol} / \mathrm{s}$ of TEA yielded primarily the $[\mathrm{M}+4 \mathrm{H}]^{4+}$ apo- and holomyoglobin with some $[\mathrm{M}+5 \mathrm{H}]^{5+}$ ions from both species. The $[\mathrm{M}+5 \mathrm{H}]^{5+}$ ion for holo-myoglobin appears significantly larger than that observed for apomyoglobin (Figure 3), but we are not certain yet that this difference is experimentally significant. Overall, there appears to be little difference in proton transfer reactivity between apo-myoglobin and holo-myoglobin. It is interesting that the holo- to apo-protein intensity ratio is increased in the product ion spectrum. This observation indicates that significant heme loss occurs via collisional dissociation. In the interface, the lower charge states produced by reaction are not collisionally activated as much as are high charge states. The horse

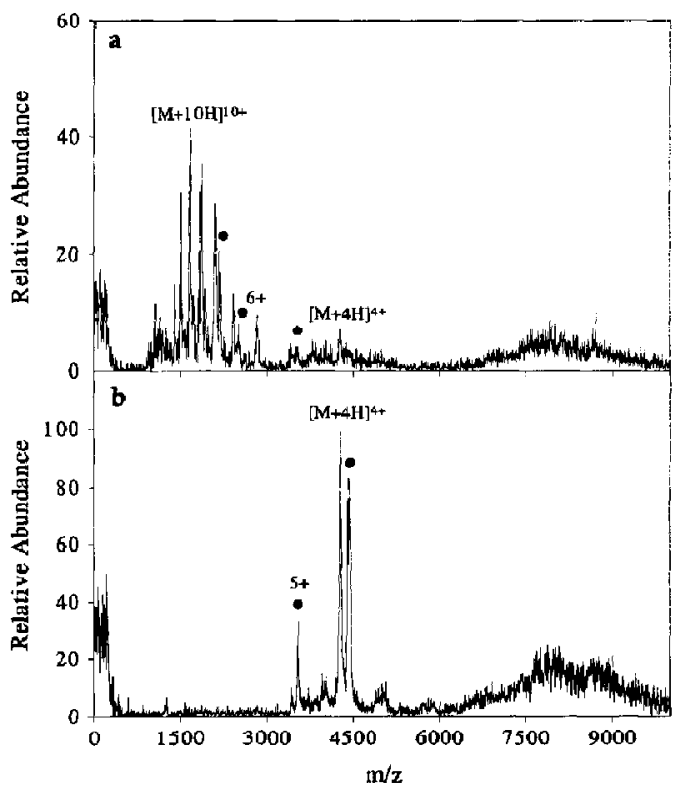

Figure 4. (a) ESI mass spectrum of horse heart myoglobin in $\mathrm{H}_{2} \mathrm{O}$ and (b) as above, but with $1.8 \times 10^{-5}-\mathrm{mol} / \mathrm{s}$ TEA. The holo-protein is indicated by solid sircles (O). heart myoglobin primary sequence contains 2 arginines, 11 histidines, and 19 lysines. Reaction with TEA thus yields slightly more charges than the number of arginines and is consistent with the residence of the remaining charges primarily on arginines.

The effect of solution conformation for bovine ubiquitin upon ESI mass spectra also has been studied [29-31]. The reactivity of 1,6-hexanediamine with ubiquitin from different solution conditions was examined (data not shown). ESI of an $\mathrm{H}_{2} \mathrm{O}$ solution with a $200{ }^{\circ} \mathrm{C}$ capillary and $100-\mathrm{V}$ OS bias yielded $10+$ to $2+$ ions. Addition of $3.0 \times 10^{-6} \mathrm{~mol} / \mathrm{s}$ of $1,6-$ hexanediamine shifted the charge state distribution to $7+$ to $1+$ with a maximum at $[\mathrm{M}+4 \mathrm{H}]^{4+}$. ESI of a $5 \%$ acetic acid/1:1 acetonitrile: $\mathrm{H}_{2} \mathrm{O}$ solution yielded $11+$ to $1+$ ions, whereas addition of $3.0 \times 10^{-6}$ $\mathrm{mol} / \mathrm{s}$ of 1,6-hexanediamine also shifted the distribution to $7+$ to $1+$ with a maximum at $[\mathrm{M}+4 \mathrm{H}]^{4+}$. Addition of $9.6 \times 10^{-6} \mathrm{~mol} / \mathrm{s}$ yielded the $4+$ to $1+$ charge states with a maximum at $[\mathrm{M}+3 \mathrm{H}]^{3+}$. No difference in proton transfer reactivity was noted for ions electrosprayed from different solution conditions. Similarly, ions from both solutions reacted with $1.8 \times$ $10^{-5} \mathrm{~mol} / \mathrm{s}$ of TEA to yield $3+$ to $1+$ ions, [2M + $5 \mathrm{H}]^{5+}$ ions, and small amounts of larger oligomer ions. (Oligomer reaction products will be discussed later.) For ions from both solutions, the product charge state of maximum intensity was $[\mathrm{M}+3 \mathrm{H}]^{3+}$, Bovine ubiquitin has 7 lysines, 1 histidine, and 4 arginines; it again appears that the reaction products retain a number of charges close to the number of arginines.

\section{Reactivity of Disulfide-Reduced versus Disulfide- Intact Protein Ions}

Figures 5 and 6 illustrate reactions of TMA with disulfide-intact and disulfide-reduced bovine proinsulin. The spectrum for the disulfide-intact protein (Figure 5a; $M_{r}=8681$; three disulfide bonds) shows charging from $[\mathrm{M}+6 \mathrm{H}]^{6+}$ to $[\mathrm{M}+2 \mathrm{H}]^{2+}$ with maximum intensity on the $5+$ ion. A capillary temperature of 120 ${ }^{\circ} \mathrm{C}$ and $75-\mathrm{V}$ OS bias were employed. The protein was electrosprayed from $5 \%$ acetic acid $/ \mathrm{H}_{2} \mathrm{O}$ with a methanol sheath. Addition of $9.0 \times 10^{-7} \mathrm{~mol} / \mathrm{s}$ of TMA shifts the charge distribution to the $2+$ to $4+$ charge states with the intensity maximum at $[\mathrm{M}+3 \mathrm{H}]^{3+}$. A relatively strong dimer ion peak at $[2 \mathrm{M}+5 \mathrm{H}]^{5+}$ also is observed in the product ion spectrum. Upon further addition of TMA, to $4.3 \times 10^{-5} \mathrm{~mol} / \mathrm{s}$, the $3+$ to $1+$ charge states are obtained with maximum intensity on the $[\mathrm{M}+2 \mathrm{H}]^{2+}$ ion (see Figure $5 \mathrm{~b}$ ). Oligomer ions $[2 \mathrm{M}+3 \mathrm{H}]^{3+}$ and $[3 \mathrm{M}+5 \mathrm{H}]^{5+}$ also are observed, which indicates that oligomer ions as well as monomer ions are charge shifted. We cannot at this point determine whether the low-charged dimer and trimer ions arise from reaction of dimer and trimer ions, respectively, or whether they reflect the products of TMA reactions with larger oligomers. 


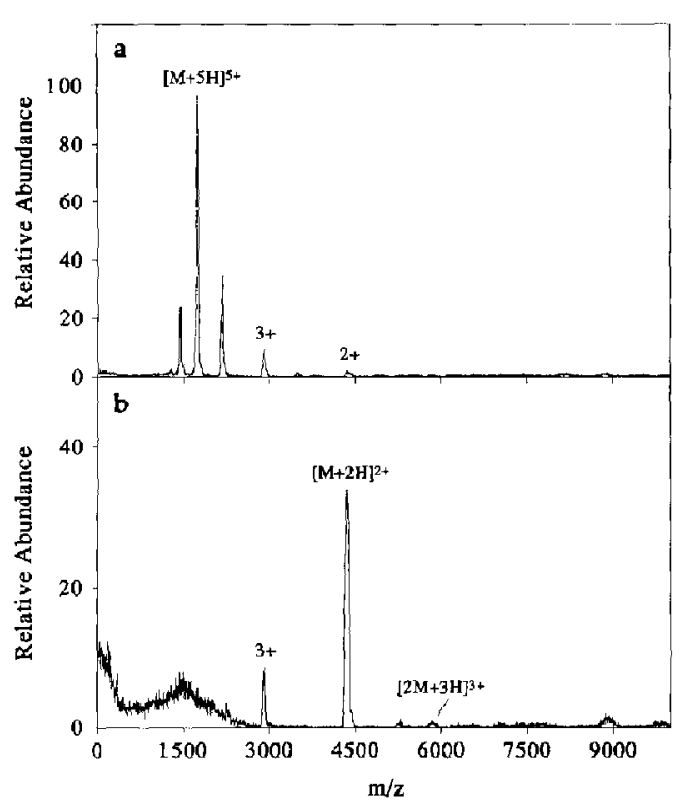

Figure 5. (a) ESI mass spectrum of bovine proinsulin electrosprayed from $5 \%$ acetic acid/water with a methanol sheath and (b) as above, but with $4.3 \times 10^{-5}-\mathrm{mol} / \mathrm{s}$ TMA.

The ESI mass spectrum for reduced bovine proinsulin is illustrated in Figure 6a. The interface conditions were the same as employed for Figure 5. Charges from $[\mathrm{M}+8 \mathrm{H}]^{8+}$ to $[\mathrm{M}+3 \mathrm{H}]^{3+}$ are observed, as are dimer inns from $[2 \mathrm{M}+13 \mathrm{H}]^{13}$ to $[2 \mathrm{M}+7 \mathrm{H}]^{7+}$. Apparently the disulfide-reduced protein forms dimers

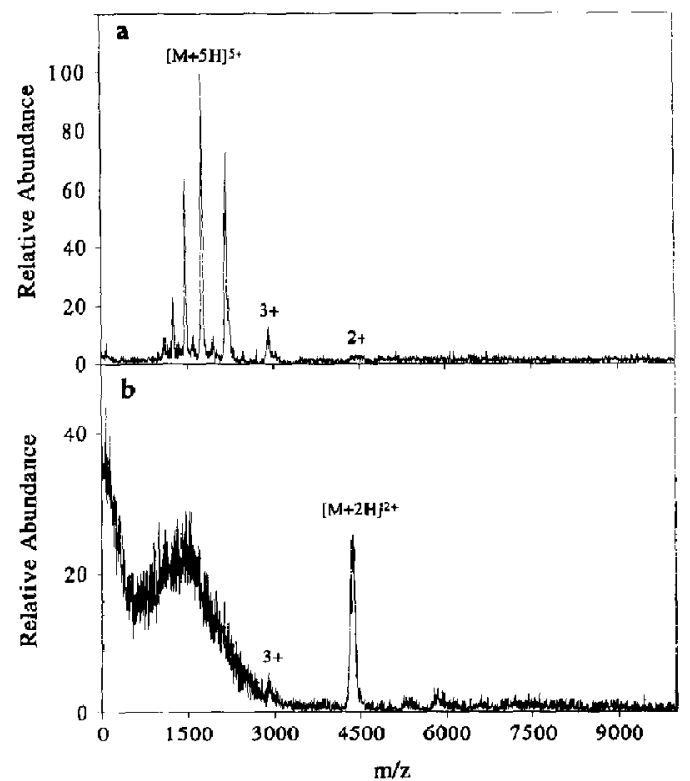

Figure 6. (a) ESI mass spectrum of reduced bovine proinsulin electrosprayed from $5 \%$ acetic acid/water with a methanol sheath and (b) as above, but with $4.3 \times 10^{-5}-\mathrm{mol} / \mathrm{s}$ TMA. with greater propensity than the disulfide-intact protein, possibly because the hydrophobic interior is exposed in the reduced protein. Addition of $9.0 \times 10^{-7}$ $\mathrm{mol} / \mathrm{s}$ of TMA reduces the charging, yielding $[\mathrm{M}+$ $3 \mathrm{H}]^{3+}$ primarily, with small contributions from $[\mathrm{M}+$ $4 \mathrm{H}]^{4+},[\mathrm{M}+2 \mathrm{H}]^{2+}$, and $[2 \mathrm{M}+5 \mathrm{H}]^{5}$. Increased TMA (to $4.3 \times 10^{-5} \mathrm{~mol} / \mathrm{s}$ ) yields $[\mathrm{M}+2 \mathrm{H}]^{2+}$ primarily, with some $[\mathrm{M}+3 \mathrm{H}]^{3+}$. There is no significant difference between the product charge distribution of "native $e^{\prime \prime}$ and reduced proinsulin with either $9.0 \times 10^{-7}$, $6.5 \times 10^{-6}$, or $4.3 \times 10^{-5} \mathrm{~mol} / \mathrm{s}$ of TMA. These results contrast with our earlier findings at $m / z<2000$ that showed increased reactivity for disulfide-intact proteins. Bovine proinsulin has 2 lysines, 2 histidines, and 4 arginines.

An ESI mass spectrum for bovine $\alpha$-lactalbumin ( $M,=14175$; four disulfide linkages) is illustrated in Figure $7 \mathrm{a}$. A 75-V OS bias and $130{ }^{\circ} \mathrm{C}$ capillary were employed. Figure $7 b$ and $c$ display spectra for $\alpha$ lactalbumin after addition of $9.0 \times 10^{7}$ and $4.3 \times 10^{-5}$ $\mathrm{mol} / \mathrm{s}$ of TMA, respectively. After reduction of the four disulfide linkages, the spectra shown in Figure 8

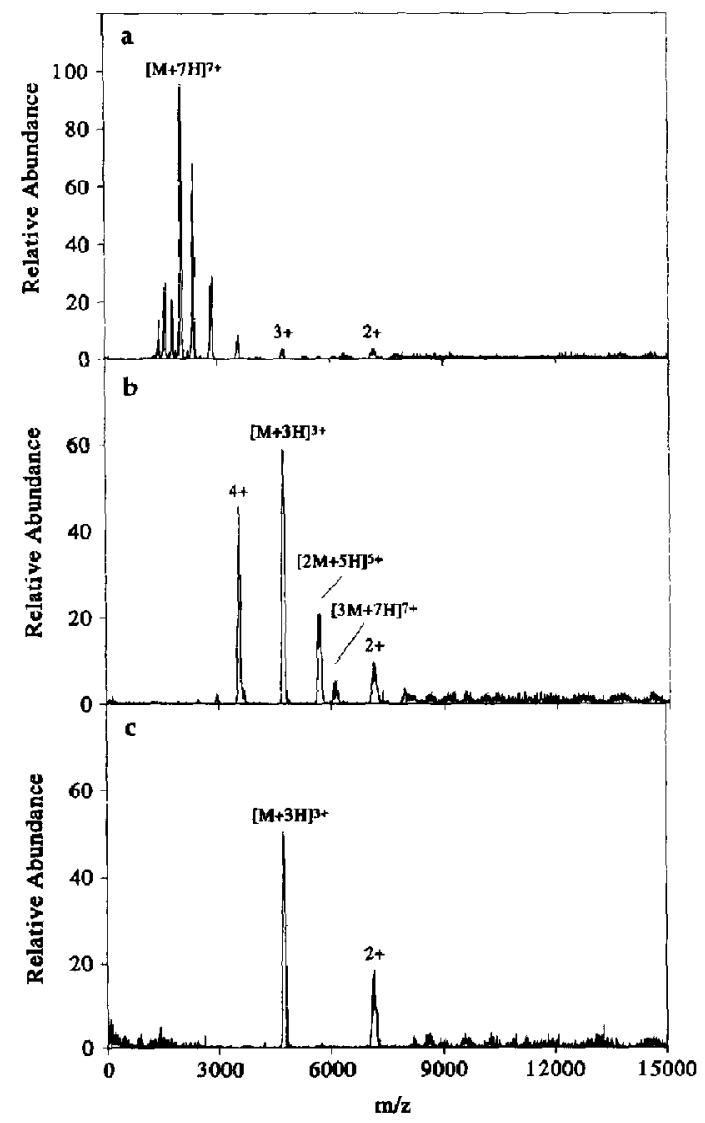

Figure 7. (a) ESI mass spectrum of bovine $\alpha$-lactalbumin electrosprayed from $5 \%$ acetic acid/water with a methanol sheath and as above, but with (b) $9.0 \times 10^{-7}-$ and (c) $4.3 \times 10^{-5}-\mathrm{mol} / \mathrm{s}$ TMA. 


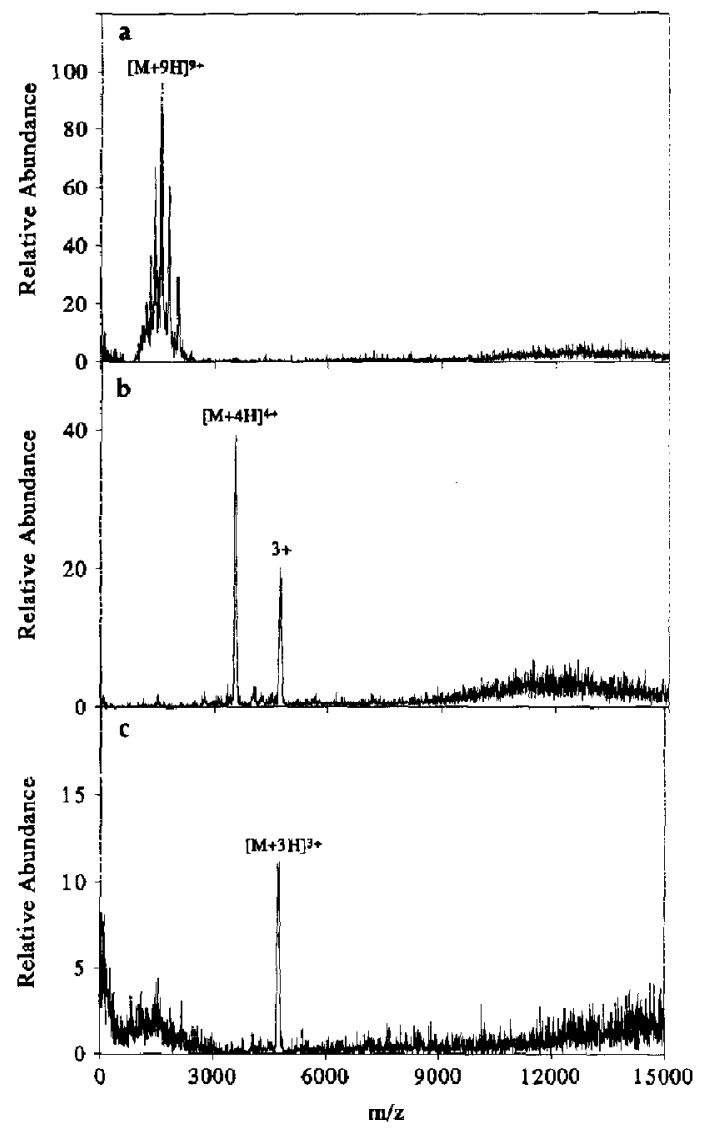

Figure 8. (a) ESI-MS of reduced bovine a-lactalbumin electrosprayed from $5 \%$ acetic acid/water with a methanol sheath and as above, but with (b) $9.0 \times 10^{-7}$ - and (c) $4.3 \times 10^{-5} \mathrm{~mol} / \mathrm{s}$ TMA.

are obtained under the same interface conditions for 0 , $9.0 \times 10^{-7}$, and $4.3 \times 10^{-5} \mathrm{~mol} / \mathrm{s}$ of TMA. Differences in the relative abundances of $[\mathrm{M}+2 \mathrm{H}]^{2+}$ and $[\mathrm{M}+$ $3 \mathrm{H}]^{3+}$ between the disulfide-intact and the disulfidereduced $\alpha$-lactalbumin are observed following proton transfer. The disulfide-linked protein yields more of the lower charge state ions, consistent with our earlier $\mathrm{m} / \mathrm{z}<2000$ studies. However, the differences in the charge state populations are not as dramatic as those observed with lower proton affinity reagents and lower reagent flows. Bovine $\alpha$-lactalbumin has 12 lysines, 3 histidines, and 1 arginine. The product ions possess slightly more charges than the number of arginines, but fewer than the sum of arginines and lysines. In contrast to our observations with proinsulin, here the disulfide-intact $\alpha$-lactalbumin showed greater dimer formation than the reduced protein. Also interesting is the observation in Figure 7 that dimer and trimer intensities increase in going from 0 to $9.0 \times 10^{-7} \mathrm{~mol} / \mathrm{s}$ of TMA, and then decrease as the TMA flow is further increased to $4.3 \times 10^{-5} \mathrm{~mol} / \mathrm{s}$. This behavior may reflect oligomer dissociation. Perhaps upon proton transfer, larger oligomer ions may shed monomers (either neutral or charged) and form dimers and trimers as energy is released from the reaction. Dimer and trimer ions may dissociate upon further reaction to yield monomer ions.

\section{Conclusions}

Only small or experimentally insignificant differences in reactivity were observed for protein ions generated from different solution conformations, although small but significant differences were noted in the reactivity of disulfide-intact versus disulfide-redused a-lactalbumin. Proinsulin showed no significant reactivity differences between disulfide-linked and disulfide-intact proteins. Apparently the proton transfer rates of widely spaced charge sites for the ions at higher mass-to-charge ratio do not reflect the compactness of "native" versus reduced proteins as strongly as do the reaction rates for higher charge states. This observation reflects the reduced electrostatic contributions to reactivity for widely spaced charges.

After reaction with the maximum amount of TEA, TMA, or 1,6-hexanediamine reagent employed, product charge states approaching the number of arginine residues were observed. The data are roughly consistent with expectations based on the proton affinities of the isolated amino acids and the electrostatic contributions from the multiple charging. Of the basic residues, arginine is expected to be least reactive to proton transter, followed by lysine and then histidines [22a]. Reactions with TMA proceed much farther than expected based on simple proton affinities, which reflects electrostatic contributions from multiple charging.

For some proteins, dimer and trimer contributions to the mass spectra increase as amine reagent is added, which we attribute to one of two possibilities: (1) they are more apparent when the oligomer ions are condensed into one charge state or (2) they are created from larger oligomers due to energy released by proton transfer from larger oligomers. In some cases oligomer ions appear only at intermediate reagent flows and disappear at higher reagent flows, which supports hypothesis 2 .

Addendum. Since the original submission of this manuscript, two relevant publications have appeared in the literature $[33,34]$.

\section{Acknowledgments}

We acknowledge support of the U.S. Department of Energy through the Office of Health and Environmental Research and through internal Exploratory Research of the Molecular Science Research Center (contract DE- $\Lambda$ C06-76RLO 1830). Pacific Northwest Laboratory is operated by Battelle Memorial Institute.

\section{References}

1. Ogorzalek Loo, R. R.; Loo; J. A.; Udseth, H. R.; Fulton, J. L.; Smith, R. D. Rapid Commun. Mass Spectrom. 1992, 6, 159-165.

2. Winger, B. E.; Light-Wahl, K. J.; Rockwood, A. L; Smith, R. D. J. Am. Chem. Soc. 1992, 114, 5897-5898. 
3. Ogorzalek Loo, R. R., Smith, R. D. I. Am. Soc. Mass Spectrom. $1994,5,207-220$.

4. Suckau, D.; Shi, Y.; Ben, S. C.; Senko, M. W.; Quiru, J. P. Wampler, F. M., Ill; Mclafferty, F. W. Proc. Natl. Acad. Sci. USA 1993, 90, 790-793.

5. (a) Covey, T. R.; Douglas, D. J. J. Am. Soc Mass Spectrom. 1993, 4, 616-623. (b) Cox, K. A.; Julian, R. K.; Cooks, R. G.; Kaiser, R. E. J. Am. Soc. Mass Spectrom. 1994, 5, 127-136.

6. Feng, R.; Konishi, Y. Proceedings of the 40th ASMS Conference on Mass Spectrometry and Allied Topics, Washington, DC, 1992; pp 1635-1636.

7. McLuckey, S, A.; Van Berkel, G. J.; Glish, G. L. J. Am. Chem. Soc, 1990, 112, 56685670

8. Feng, R.; Konishi, Y. Proceedings of the 41st ASMS Conference on Mass Spectrometry and Allied Topics, San Francisco, CA, 1993; pp 1020a-1020b.

9. Konishi, Y.; Feng, R. Proceedings of the 40th ASMS Conference on Mass Specirometry and Allicd Topics, Washington, DC, 1992; PP 625-626.

10. Ogorzalek Loo, R. R.; Udseth, H. R.; Smith, R. L. 1. Phys. Chem. 1991, 95, 6412-6415.

11. Ogorzalek Loo, R. R.; Udseth, H. R.; Smith, R. D. J. Am. Soc. Mass Spectrome. 1992, 3, 695-705.

12. Winger, B. E.; Light-Wahl, K. J.; Smith, R. D. 1. Am. Sac. Mass Spectrom., 1992, 3, 624 630 .

13. Winger, B. E.; Light-Wahl, K. J.; Ogorzalek Loo, R, R.; Udseth, H. R.; Smith, R. D. I. An. Soc. Mass Spectrom., 1993, 4, $536-545$.

14. Ikonomou, M. G.; Kebarle, P. Int. J. Mass Spectroth. Ion Processes 1992, 117, 283-298.

15. McLuckey, S. A.; Van Bcrkel, G. J.; Glish, G. L. Proc. 38th ASMS Conference on Mass Spectrometry and Allied Topics, Tucson, $A Z, 1990 ; \mathrm{pp} 1134-1135$.

16. McLuckey, S. A.; Glish, G. L.; Van Berkel, G. J. Anal. Chem. $1991,63,1971-1978$.
17. McLuckey, S. A.; Glish. G. L.; Van Berkcl, G. J. Proc. 39th ASMS Conference on Mass Spectrometry and Allied Topics, Nashville, TN, 1991, pp 901-902.

18. Rockwood, A. L.; Busman, M.; Udseth, H. R.; Smith, R. D. Rapid Commun. Mass Spectrom. 1991, 5, 582-585.

19. Busman, M.; Rockwood, A. L.; Smith, R. L. I Phys Chem. $1992,96,2397-2400$.

20. Beuhler, R. J.; Friedman, L. J. Chem. Phis. 1982, 77, 2549.

21. Meot-Ner (Mautner), M.; Sieck, L. W. I. Am. Chem. Soc. 1991, $113,4448-4460$.

22. (a) Gorman, G. S.; Speir, J. P.; Turner, C. A.; Amsterr, 1. J. 1. An. Chem. Soc. 1992, 114, 3986-3988; (b) Lias, S. G.; Liebman, J. F.; Levin, R.D. I. Phys. Chem. Ref. Dala 1984, 13, 695-808.

23. Chowdhury, S. K.; Katta, V; Chait, B. T. 1. Am. Chem. Soc. 1990, 112, 9012-9013.

24. Bojeson, G. J. Am. Chem. Soc. 1987, 109, 55575558.

25. Locke, M. J.; McIver, R. J. Am. Chem. Soc. 1983, 105, 4226-4232.

26. Katta, V.; Chait, B. T. J. Awr. Chemt. Soc. 1991, 113, 8534-8535.

27. Loo, J. A.; Giordani, A. B.; Mucnster, H. Rapid Communt. Mass Spectrom. 1993, 7, 186-189.

28. Zaia, J.: Annan, R. S.; Biemann, K. Rapid Commun. Mass Spectrom. 1992, 6, 32-36.

29. Loo, J. A.; Ogorzalek Loo, R. R.; Udseth, H. R.; Edmonds, C. G.; Smith, R. D. Rapid Commum. Mass Spectrom. 1991, 5, 101.

30. Katta, V.; Chait, B. T. I. Am. Chem. Soc. 1993, 115, 6317 .6321.

31. Mirza, U. A.; Cohen, S. L.; Chait, B. T. Anal. Chem. 1993, 65, $1-6$.

32. Winger, B. E.; Light-Wahl, K. J.; Smith. R. D. Proceedings of the 40th ASMS Conference on Mass Spectrometry and Allied Topics, Washington, DC, 1992, pp 481-482

33. Hunter, A. P.; Severs, J. C.; Harris, F. M.; Games, D. E. Rapid Commun. Mass Spectrom. 1994, 8, 417-422.

34. Cassady, C. J.; Wronka, J.; Kruppa, G. H.; Laukien, F. H. Kapid Commun. Mass Spectrom. 1994, 8, 394-400. 